\title{
Macrocycle Therapeutics to Treat Life-threatening Diseases
}

\author{
Gokhan Batur, Philipp Ermert, Johann Zimmermann, and Daniel Obrecht*
}

Dedicated to Dr. J.-P. Obrecht

\begin{abstract}
Polyphor's macrocycle platform led to the discovery of novel antibiotics addressing specifically Gramnegative bacteria by targeting outer membrane proteins. Furthermore, POL6014, an inhibitor of neutrophile elastase and balixafortide, a CXCR4 inhibitor have been discovered and developed from the platform. Currently a combination of balixafortide and eribulin is in Phase III clinical trial for the treatment of patients with advanced metastatic HER2-negative breast cancer.
\end{abstract}

Keywords: Antibiotic $\cdot$ Breast cancer $\cdot$ CXCR4 inhibitor $\cdot$ Macrocycle $\cdot$ Protein epitope mimetic

\section{Introduction: A Short History of Polyphor Ltd}

Polyphor Ltd was founded in November 1996 and started operations in laboratories at the University of Zurich in early 1997. In collaboration with the research group of Professor John A. Robinson at the University of Zurich the company developed a proprietary macrocycle-based discovery platform with the aim to address novel therapeutic targets with high unmet medical need. Besides applying the macrocycle platform in collaboration with Pharma partners, the company explored the potential of the platform to initiate its own drug discovery and development projects. The focus of internal programs was on a novel class of antibiotics against key Gram-negative bacteria, inhibitors of chemokine receptors (e.g. CXCR4, CXCR7, CCR10), and inhibitors of serine proteases (neutrophil elastase, tryptase, cathepsin G). In 2008 the company moved completely to Allschwil, where it found an ideal home and a stimulating environment for its further development. In 2017, the company decided to place the focus on further development of its key clinical assets balixafortide (POL6326), murepavadin (POL7080), and POL6014. In early 2018, the inhaled elastase inhibitor POL6014 was licensed to Santhera Pharmaceuticals. In May 2018, Polyphor made a very successful IPO at the Swiss Stock Exchange (Six).

\section{Macrocycle-based Technology Platform}

Many of the novel emerging targets involve large surface protein-protein interactions (PPIs) where medium-sized macrocycles (MW range 500-2000 Da) have been proposed as potential ligands. ${ }^{[1]}$

Two different macrocyclic approaches were developed at Polyphor (Fig. 1, Fig. 2):

a) Conformationally constraint macrocyclic peptides mimicking key epitopes displayed on the surface of bioactive peptides and proteins such as the $\beta$-hairpin and the $\alpha$-helix (PEMfinder, PEM: protein epitope mimetics) in the molecular weight range of 700-2000 Da (6 to 20 amino acids) containing sequences derived from bioactive peptide ligands. ${ }^{[2]}$

b) Non-peptide-derived macrocycles in molecular-weight range 500-800 Da (MacroFinder) mimicking key turn and loop-like structures observed in bioactive peptide ligands..$^{[3]}$

PEMfinder molecules are applicable mainly for complex extracellular targets including PPIs and are administered parenter- ally and/or by inhalation. ${ }^{[2 b]}$ In contrast, MacroFinder molecules have a smaller MW and have been designed to also address intracellular PPIs. ${ }^{[4]}$ In recent years several articles have highlighted the unique features of macrocycles to address complex molecular targets and rules for achieving cell permeability and oral bioavailability. ${ }^{[2 b, 5]}$ First, their larger size compared to small molecules allows them to bind to 'hot spots' with binding sites typically in the range of 800-1200 $\AA^{2[6]}$ and second, their conformational semi-rigidity provides the necessary flexibility for induced fit. ${ }^{[7]}$

\section{OMPTA: A Novel Class of Antibiotics}

The global emergence of pan-resistant bacterial strains combined with a dry pipeline of novel antibiotics with novel mechanisms of action increase the chances of a global antibiotic crisis. ${ }^{[8]}$ The WHO has issued a priority pathogen list (PPL) of antibiotic resistant bacteria which currently constitute a severe threat to society. ${ }^{[9]}$ Priority 1 pathogens include carbapenem-resistant Pseudomonas aeruginosa (Pa), Acinetobacter baumannii (Ab), and third-generation cephalosporin-resistant and carbapenemresistant Enterobacteriaceae, all belonging to Gram-negative bacteria.

In collaboration with the University of Zurich, Polyphor has developed a novel class of antibiotics (outer membrane protein targeting antibiotics OMPTA) ${ }^{[2 b]}$ that specifically addresses Gramnegative bacteria. Inspired from sequences of antimicrobial peptides (AMPs) and host defense peptides (HDPs) libraries of PEM molecules were synthesized and tested against a panel of Gramnegative bacteria.[2a] Initial hits were subsequently optimized by a multi-dimensional medicinal chemistry approach. Three programs addressing different outer membrane protein targets (Fig. 3) led to prototypical OMPTA molecules with novel mechanisms of action and differing antimicrobial spectrum (Fig. 4).

Murepavadin (POL7080) (Fig. 2), the first antibiotic of the OMPTA class that was discovered and developed, is potent and pathogen-specific against $\mathrm{Pa}$ including multidrug resistant (MDR), extensively drug resistant (XDR) and colistin-resistant strains (Fig. 3). ${ }^{[10]}$ Mechanism of action studies unambiguously showed that murepavadin binds to the lipopolysaccharide transport protein (LptD) at the periplasmic jellyroll domain blocking the translocation of lipopolysaccharide (LPS) from the periplasm to the outer membrane (Fig. 3). ${ }^{[10,11]}$ Murepavadin is currently in 


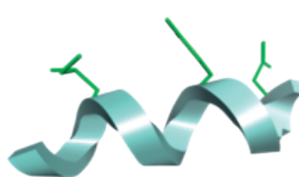

$\alpha$-helix

$800-1500 \AA^{2}$

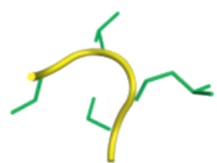

ß-turn $400-600 \AA^{2}$

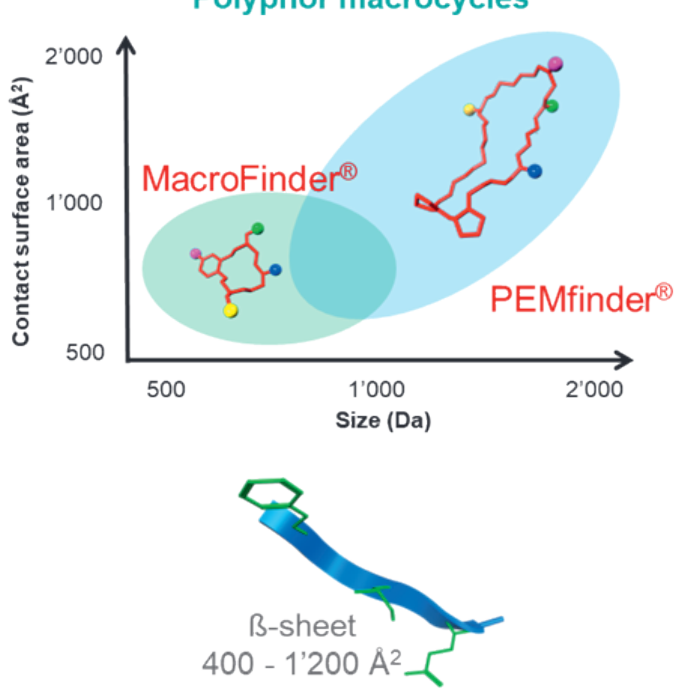

\section{Balixafortide (POL6326) CXCR4}

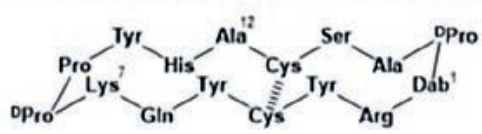

Murepavadin (POL7080) LptD

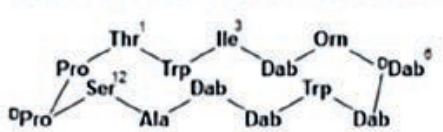<smiles>C1CCCCC1</smiles>

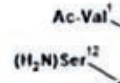

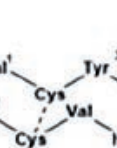<smiles>[14CH3]</smiles>

Thanatin LptA

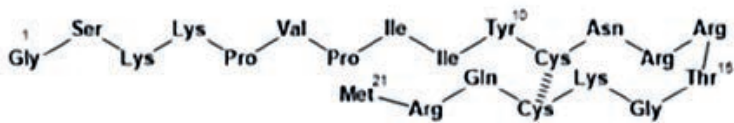

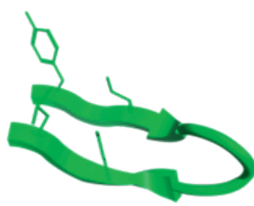

ß-hairpin $600-2000 \AA^{2}$

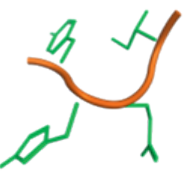

non-canonical "omega loops" $600-800 \AA^{2}$
Fig. 1. Polyphor's macrocycle platform is composed of PEMfinder (macrocyclic peptides MW: 700-2000 Da; 35'000 cpds) and MacroFinder (non-peptide macrocycles MW: 500-850 Da; 20’000 cpds).
Fig. 2. Polyphor's development compounds are derived from its proprietary macrocycle platform.
Phase I clinical development as an inhaled formulation to treat people with cystic fibrosis $(\mathrm{CF})$. $^{[8 \mathrm{~b}, 12]}$

The second OMPTA class consists of chimeric macrocyclic antibiotics containing two pharmacophores targeting LPS and BamA, two key essential targets located in proximity at the outer membrane of Gram-negative bacteria. ${ }^{[13]}$ BamA is a $\beta$-barrel protein and part of the BAM ( $\beta$-barrel assembly machinery), which is critical for the folding and integration of $\beta$-barrel proteins in the outer membrane. ${ }^{[14]}$ These antibiotics show a unique spectrum of activity by targeting all WHO priority 1 pathogens (Fig. 4). POL7306 (structure currently undisclosed) and its closely related analogue compound $7^{[13]}$ (Fig. 2) are representative lead molecules that showed potent antimicrobial in vitro activity which translated also in good in vivo activity in various murine animal infection models including MDR, XDR and colistin-resistant strains. ${ }^{[13]}$ Further optimization is currently ongoing in view to discover and nominate a candidate for further preclinical and clinical studies. This program obtained significant funding from CARB-X.

Finally, in collaboration with Professor Oliver Zerbe at the University of Zurich, a program was initiated in 2019 to develop analogues of thanatin, a 21 amino acid residue antimicrobial peptide isolated from the hemipteran insect Podisus maculiventris (soldier bug) with antimicrobial and antifungal activity.[15] The primary mechanism of action responsible for the Gramnegative activity of thanatin was identified only recently. ${ }^{[16]}$ Thanatin interacts in the periplasm at the LptD-LptA interface by binding to the N-terminal jellyroll region of lipopolysaccharide transport protein A (LptA), thereby inhibiting proper LPS transport across the periplasm (Fig. 3). The peptide exhibits a $\beta$-hairpin conformation in solution which is key for its interaction with LptA. ${ }^{[8 b, 17]}$ In order to improve the low in vitro plasma stability and short in vivo half-life, Polyphor has initiated a peptide optimization program which resulted in thanatin derivatives with significantly improved antimicrobial activity and druglike properties. Thanatin derivatives show potent activity against carbapenem-resistant and third generation cephalosporin resistant Enterobacteriaceae which are key pathogens contributing to the antimicrobial resistance (AMR) problem. This program is at hitto-lead optimization stage and receives significant funding from Innosuisse and CARB-X. 


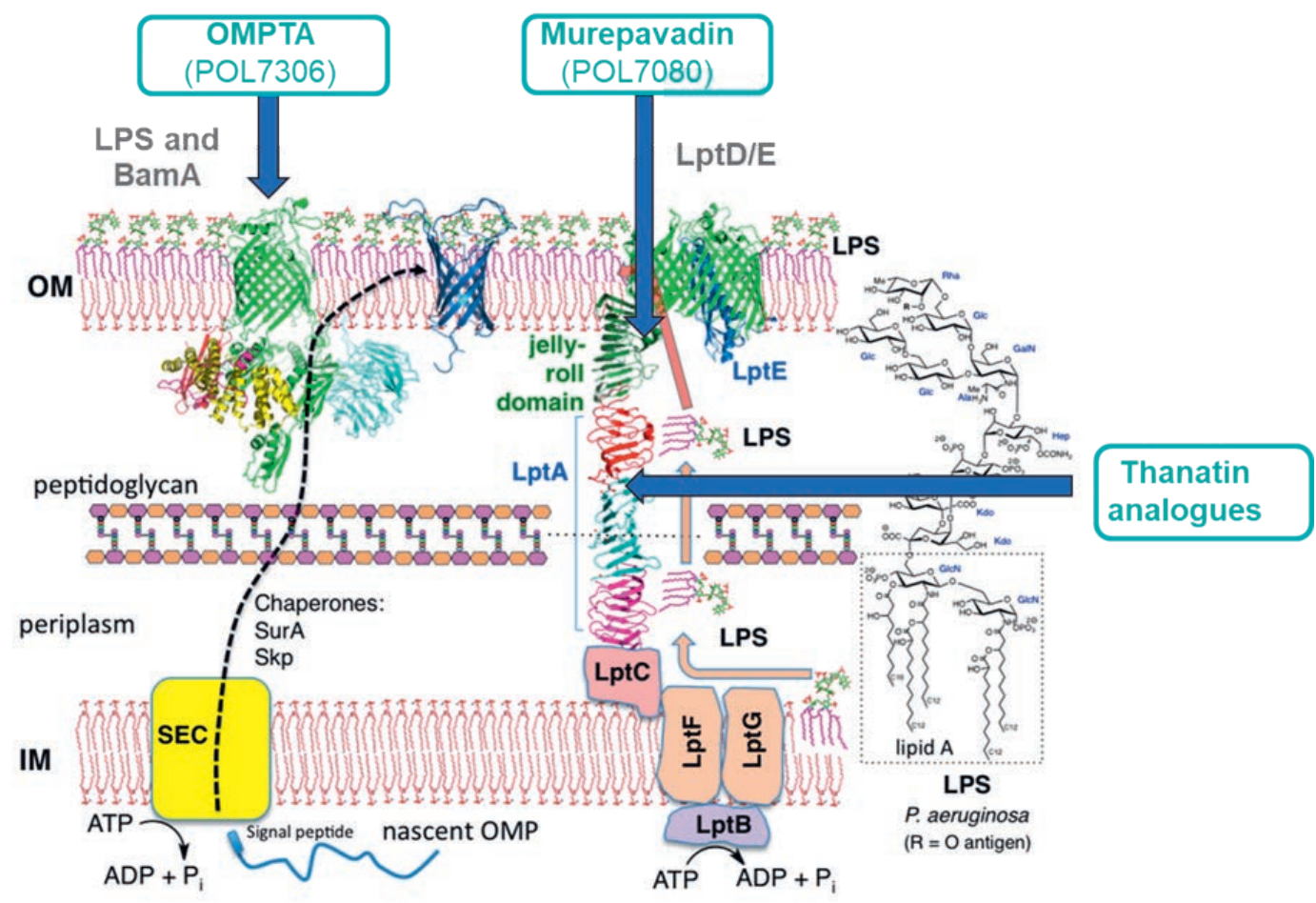

Fig. 3. Targets of outer membrane protein targeting antibiotics (OMPTA).

\begin{tabular}{|c|c|c|c|c|c|}
\hline Group & Species & Murepavadin & $\begin{array}{c}\text { POL7306 } \\
\text { and cpd } 7 \text { [193 } \\
\end{array}$ & $\begin{array}{c}\text { Thanatin } \\
\text { Iderivatives }\end{array}$ & Colistin \\
\hline \multirow[t]{7}{*}{ Enterobacteriacese: } & Escherichia coli & & & & \\
\hline & Klebsiella spp. & & & & \\
\hline & Citrobacter spp. & & & & \\
\hline & Enterobacter spp. & & & & \\
\hline & Salmonella spp. & & & & \\
\hline & Shigella spp. & & & & \\
\hline & Proteus spp. & & & & \\
\hline \multirow[t]{3}{*}{ Non-fermenters: } & Pseudomonas aeruginosa & & & & \\
\hline & Acinetobacter baumannii & & & & \\
\hline & Steno. maltophilia & & & & \\
\hline $\begin{array}{l}\text { Gram-negatives with } \\
\text { acquired colistin resistance: }\end{array}$ & $\begin{array}{l}\text { K. pneumoniae, E.coli, Enterobacter } \\
\text { spp., A. baumannii, } \boldsymbol{P} \text {. aeruginosa }\end{array}$ & $\begin{array}{l}\text { Col-R } \\
\text { Preruginasa }\end{array}$ & & & \\
\hline \multirow[t]{2}{*}{ Other Gram-negatives: } & Haemoohilus influenzae & & & NT & \\
\hline & Moraxella catarthalis & & & & \\
\hline Gram-positives: & Stapylococcus spp., Streptococcus spp. & & & & \\
\hline
\end{tabular}

Fig. 4. Overall spectrum of antimicrobial activity of OMPTA molecules.

\section{high activity medium activity no activity}

\section{Balixafortide: Best in Class CXCR4 Inhibitor}

The CXCR4 chemokine receptor and its ligand CXCL12 $(\mathrm{SDF}-1 \alpha)$ form a key signaling axis that is implicated in several important biological processes and human diseases. ${ }^{[18]}$ Several classes of CXCR4 modulating molecules, such as small molecules, peptide and peptide mimetics, and therapeutic antibodies have been described and investigated. ${ }^{[19]}$ Peptidomimetic compounds in particular have led to development of potent therapeutically powerful inhibitors. ${ }^{[19 b, 20]}$ One of the first CXCR4 inhibitors described was polyphemusin II (Fig. 5), a naturally occurring 18-amino acid peptide isolated from the American horseshoe crab (Limulus polyphemus), as well as the closely related synthetic analogue T22. ${ }^{[21]}$ A $\beta$-hairpin conformation stabilized by two intramolecular disulfide bonds was observed for Polyphemusin II and T22 ([Tyr ${ }^{5,12}$, Lys $\left.{ }^{7}\right]$-polyphemusin II) by solution NMR and seems critical for the binding to CXCR4 (Fig. 6). ${ }^{\text {[2] }] ~ S h o r t e n e d ~}$ analogues of polyphemusin II maintaining the $\beta$-hairpin structure led to the discovery of TC140. ${ }^{[23]}$ Inspired by this work Polyphor applied its PEM technology and synthesized a series of analogues which led to P0001689 with potent CXCR4 inhibition $\left(\mathrm{IC}_{50}=15\right.$ nM; Ca-flux) (Fig. 5). ${ }^{[20]}$ In a subsequent optimization roughly 200 analogues were designed, synthesized and tested. The focus was to further stabilize the $\beta$-hairpin bioactive conformation, improve plasma stability and potency. This effort led to POL3026 and POL2438 with excellent CXCR4 inhibitory activity $\left(\mathrm{IC}_{50}=\right.$ $1.2 \mathrm{nM}$ and $1.9 \mathrm{nM}$, respectively). Further optimization with the aim of improving selectivity, PK and safety while maintaining potency led finally to POL6326 (balixafortide; Fig. 5) which was nominated for further preclinical and then clinical development. Balixafortide is a 16 -amino acid residue cyclopeptide $\beta$-hairpin mimetic with one intramolecular disulfide bond. The importance of $\beta$-hairpin mimicry was recently shown by an X-ray structure of a PEM inhibitor bound to CXCR4 (Fig. 6). ${ }^{[24]}$

The therapeutic potential for CXCR4 ligands includes stem cell mobilization, HIV-1 infection, cancer, and immune systemrelated disorders. ${ }^{[18 a, 19 b]}$ Recently, the rich biology of the CXCR4- 


\section{Hit exploration \\ ( 80 cpds) \\ - Synthesis of \\ reference cpds \\ Find new scaffolds \\ $1^{\text {st }}$ Optimization \\ ( 200 cpds) \\ Improved plasma \\ stability \\ - Improved potency \\ $2^{\text {nd }}$ Optimization \\ ( 1300 cpds $)$ \\ - Maintained potency \\ - Improved selectivity \\ - Improved safety}
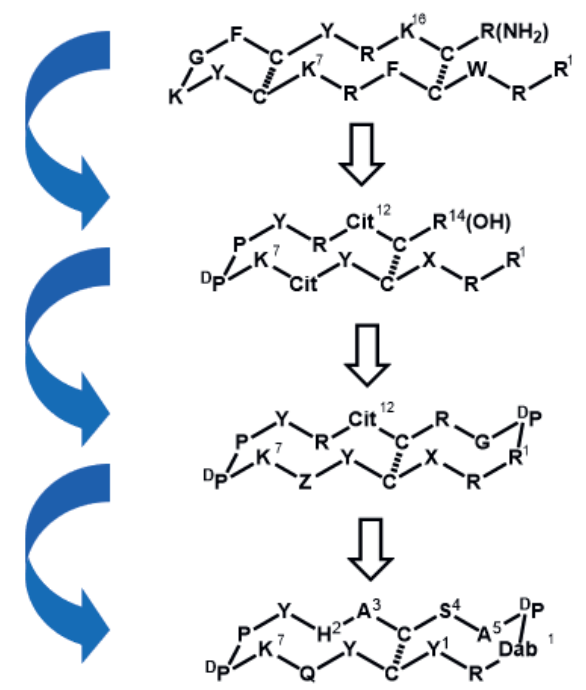

\section{Balixafortide}

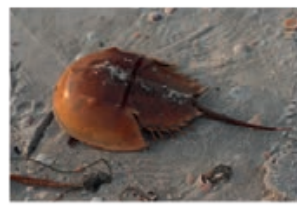

American horseshoe crab (Limulus polyphemus)
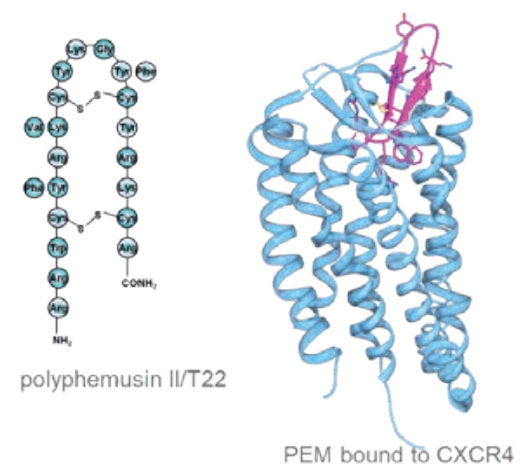

Polyphemusin-II

-1992: Tamamura \& Fujii

- polycationic

- hemolytic

- low plasma stability

P0001689 (analogue of TC140)

-Tamamura \& Fujii

$-\mathrm{IC}_{50}=15.5 \mathrm{nM}$ (Ca-flux)

POL3026

( $\mathrm{Z}=\mathrm{Q} ; \mathrm{X}=$ 2-naphthyl-alanine);

$\mathrm{IC}_{50}=1.2 \mathrm{nM}$ (Ca-flux)

POL2438

(Z=Cit; X= 2-naphthyl-alanine)

$\mathrm{IC}_{50}=1.9 \mathrm{nM}$ (Ca-flux)

POL6326 (Balixafortide)

$\mathrm{IC}_{50}=3.5 \mathrm{nM}$ (Ca-flux)
Fig. 5. Balixafortide optimization process. balixafortide was comparable to that of eribulin monotherapy. A pivotal Phase III trial is ongoing (NCT03786094).

Balixafortide is well tolerated and is therefore an excellent candidate drug for other combination approaches. For example, balixafortide demonstrated in a humanized breast cancer PDX model (murine patient derived xenograft model) strong synergistic efficacy with paclitaxel, another tubulin binding drug with different mode of action compared to eribulin. ${ }^{[32]}$ The efficacy in combination (T/C 13\%, partial remission) was statistically superior ( $\mathrm{p}<0.0012 \mathrm{w}$ Anova) to paclitaxel alone (T/C 42\%). According to RECIST criteria, such T/C 13\% / 87\% inhibition of tumor volume in the combination arm is rated as partial remission (Fig. 7).

Fig. 6. American horseshoe crab, polyphemusin II/T22, X-ray structure of a PEM inhibitor bound to CXCR4. ${ }^{[24]}$

CXCL12 axis and its potential preclinical and clinical applications in oncology was reviewed. ${ }^{[25]}$ Balixafortide and other PEM CXCR4-targeting analogues were evaluated in preclinical studies, such as in stem cell mobilization and cancer. ${ }^{[26]}$ For instance, significantly higher hematopoietic stem cell (HSC) mobilization was achieved than for the approved drug plerixafor.[27]

Polyphor evaluated opportunities for clinical development in solid tumor indications. Three facts led finally to develop balixafortide in breast cancer:

1) Epidemiology: CXCR4 is overexpressed in human breast cancer and metastatic tumor relative to normal breast tissue. [28]

2) Prognosis and survival: there is a strong negative correlation of CXCR4 expression with overall and disease-free survival of breast cancer patients. ${ }^{29]}$

3) Preclinical data: PEM CXCR4 inhibitors demonstrated synergistic activity when combined with the microtubule binding drug eribulin in two orthotopic models of triple negative breast cancer to significantly reduce distant metastasis. ${ }^{[30]}$

Clinical proof-of-concept in combination with eribulin was recently demonstrated in a Phase I single arm dose-escalation trial in patients with metastatic HER2-negative breast cancer (NCT01837095). ${ }^{[31]}$ The objective response rate in the expanded cohort (where patients received a dose of $5.5 \mathrm{mg} / \mathrm{kg}$ balixafortide and $1.4 \mathrm{mg} / \mathrm{m}^{2}$ eribulin) was $38 \%$ (median duration 4.4 months), and the clinical benefit rate was $63 \%$ (median duration 8.1 months). This favourable therapeutic effect was clearly balixafortide dose dependent with lower efficacy in two lower dose groups 1 and 2. Tolerability and safety of eribulin in combination with

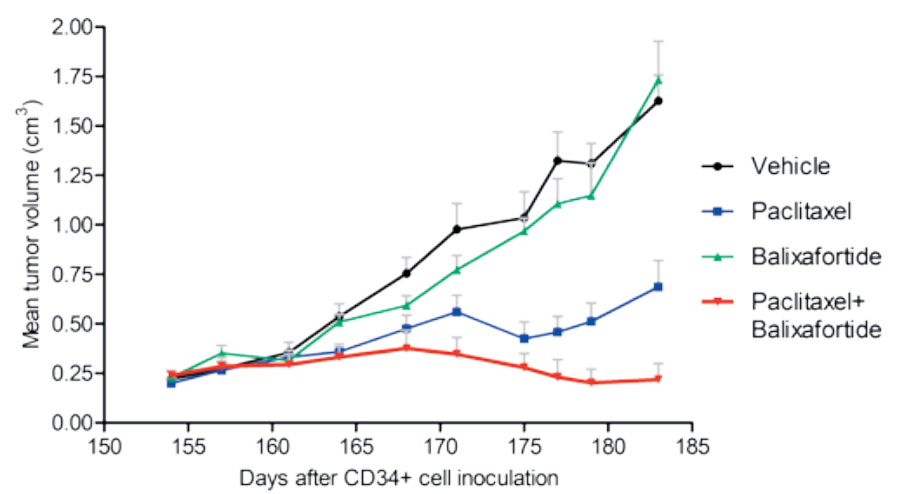

Fig. 7. Efficacy of balixafortide - paclitaxel combination compared to single agent anti-tumor activities in a murine patient derived xenograft (PDX) model.

\section{Summary and Outlook}

We are a company committed to discovering and developing best-in-class molecules in oncology and antimicrobial resistance leveraging the company's leading macrocyclic peptide technology platform. In 2020, Polyphor has demonstrated the capacity to deliver on our strategic plan despite challenging circumstances in the pandemic, rapidly advancing its pipeline and most notably, successfully completing the enrolment of the balixafortide Phase III study with 432 patients. Our priorities for 2021 are to reach the critical data readout for this study and to initiate on the inhaled murepavadin Phase I program for cystic fibrosis (CF). We will also continue with our efforts to establish a pipeline of potentially 
transformative new oncology and antibiotic candidates and new indications for balixafortide.

Balixafortide in particular can provide substantial benefit for patients in advanced HER2-negative breast cancer in combination with a chemotherapy, eribulin. Despite the number of therapy options available, advanced or metastatic HER2-negative breast cancer remains incurable and a major cause of mortality and morbidity in women. In HER2-negative advanced breast cancer with patients who have received two chemotherapies prior, eribulin is the only approved chemotherapy that has shown survival benefit versus standard of care. The median survival rate in this study has been on average 13.1 months (median), showing the substantial unmet need in this stage of the breast cancer. ${ }^{[33]}$ Therefore, balixafortide could provide substantial additional benefit to women with advanced breast cancer in combination with eribulin depending on the Phase III outcomes. If approved, balixafortide would be the first CXCR4 inhibitor for a solid tumor indication spearheading a novel immuno-oncology approach.

Beyond oncology, Polyphor has discovered a novel class of antibiotics, the Outer Membrane Protein Targeting Antibiotics (OMPTA). This new class has the potential to provide breakthrough treatment options for difficult to treat infections caused by Gram-negative bacteria (including XDR strains). In our research and development, we exclusively focus on WHO priority 1 pathogens which are the most critical group of multidrug resistant bacteria that pose a particular threat to public health. Within OMPTA class, inhaled murepavadin is our most advanced product candidate currently in Phase I development for CF. Infections will remain a major problem in CF post cystic fibrosis transmembrane conductance regulator (CFTR) modulator era as patients live longer. Pseudomonas aeruginosa $(\mathrm{Pa})$ is estimated to account for more than half of the chronic infections in CF. It is the leading cause of exacerbations, lung function decline and mortality in CF. In contrast to commonly used broad-spectrum antibiotics, murepavadin is pathogen specific. This makes it a precision medicine, highly potent against $\mathrm{Pa}$, including most resistant strains, with a reduced risk of increasing resistance in other pathogens.

Since its establishment in 1996, it has been an exciting journey for Polyphor to establish a novel peptide based chemical platform and transform to a late stage publicly listed biotechnology company. In summary, we are encouraged that our products have the potential to bring significant benefits to patients.

\section{Acknowledgements}

The authors would like to acknowledge funding from Innosuisse, CARB-X and financial support from the REPAIR Impact Fund (Novo Holdings).

Received: April 14, 2021

[1] a) T. Clackson, J. A. Wells, Science 1995, 267, 383, htpps://doi.org/10.1126/science.7529940; b) E. M. Diggers, S. P. Hale, J. Lee, N. K. Terrett, Nat. Rev. Drug Discovery, 2008, 7, 608 , htpps://doi.org/10.1038/nrd2590 https://doi.org/10.1038/nrd2590., 608, htpps://doi.org/10.1038/nrd2590 https://doi.org/10.1038/nrd2590.

[2] a) D. Obrecht, E. Chevalier, K. Moehle, J. A. Robinson, Drug Discov. Todav: Technol. 2012, 9, e63, https://doi.org/10.1016/j.ddtec.2011.07.006; b) A. Luther, K. Moehle, E. Chevalier, G. Dale, D. Obrecht, Curr. Opin. Chem. Biol. 2017, 38, 45, http://dx.doi.org/10.1016/j.cbpa.2017.02.004.

[3] a) J. Gavenonis, B. A. Sheneman, T. R. Siegert, M. R. Eshelman, J. A. Kritzer, Nat. Chem. Biol. 2014, 10, 716, https://doi.org/10.1038/nchembio.1580; b) T. R. Siegert, M. J. Bird, K. M. Makwana, J. A. Kritzer, J. Am. Chem. Soc. 2016, 138, 12876, https://doi.org/10.1021/jacs.6b05656.

[4] Ph. Ermert, K. Moehle, D. Obrecht, 'Macrocycles in Drug Discovery', Ed. J. Levin, The Royal Society of Chemistry, Cambridge, 2015, p. 283.

[5] a) F. Giordanetto, J. Kihlberg, J. Med. Chem. 2014, 57, 278, https://dx.doi.org/10.1021/jm400887j; b) B. Over, P. Matsson, C. Tyrchan, P. Artursson, B. C. Doak, M. A. Foley, C. Hilgendorf, S. E. Johnston,
M. D. Lee IV, R. J. Lewis, P. McCarren, G. Muncipinto, U. Norinder, M. W. D. Perry, J. R. Duvall, J. Kihlberg, Nature Chem. Biol. 2016, 12, 1065, https://doi.org/10.1038/nchembio.2203; c) M. R. Naylor, A. T. Bockus, M-J. Blanco, R. S. Lokey, Curr. Opin. Chem. Biol. 2017, 38, 141, https://dx.doi.org/10.1016/j.cbpa.2017.04.012.

[6] E. A. Villar, D. Beglov, S. Chennamadhavuni, J. A. Porco Jr., D Kozakov, S. Vajda, A. Whitty, Nat. Chem. Biol. 2014, 10, 723, https://dx.doi.org/10.1038/nchembio.1584.

[7] A. Whitty, M. Zhong, L. Viarengo, D. Beglov, D. R. Hall, S. Vajda, Drug Discov. Today 2016, 21, 712, https://dx.doi.org/10.1016/j.drudis.2016.02.005.

[8] a) A. Luther, C. Bisang, D. Obrecht, Bioorg. Med. Chem. 2018, 26, 2850, http://doi.org/10.1016/j.bmc.2017.08.006; b) G. Upert, A. Luther, D. Obrecht, P. Ermert, Med. Drug Discovery, 2021, 9, 100078 , https://dx.doi.org/10.1016/j.medidd.2020.100078.

[9] E. Tacconelli, N. Magrini, WHO | Global priority list of antibiotic-resistant bacteria to guide research, discovery, and development of new antibiotics, World Health Organization, February 27, 2017.

[10] N. Srinivas, P. Jetter, B. J. Ueberbacher, M. Werneburg, K. Zerbe, J. Steinmann, B. Van der Meijden, F. Bernardini, A. Lederer, R. L. A. Dias, P. E. Misson, H. Henze, J. Zumbrunn, F. O. Gombert, D. Obrecht, P. Hunziker, S. Schauer, U. Ziegler, A. Käch, L. Eberl, K. Riedel, S. J. DeMarco, J. A. Robinson, Science, 2010, 327, 1010, https://doi.org/10.1126/science.1182749.

[11] G. Andolina, L-C. Bencze, K. Zerbe, M. Müller, J. Steinmann, H. Kocherla, M. Mondal, J. Sobek, K. Moehle, G, Malojčić, B. Wollscheid, J. A. Robinson, ACS Chem. Biol. 2018, 13, 666, https://doi.org/10.1021/acschembio.7b00822.

[12] I. Martin-Loeches, G. E. Dale, A. Torres, Expert Rev. Anti-Infect. Ther. 2018 16, 259, https://doi.org/10.1080/14787210.2018.1441024.

[13] A. Luther, M. Urfer, M. Zahn, M. Müller, S-Y. Wang, M. Mondal, A. Vitale, J-B. Hartmann, T. Sharpe, F. Lo Monte, H. Kocherla, E. Cline, G. Pessi, P. Rath, S. M. Modaresi, P. Chiquet, S. Stiegeler, C. Verbree, T. Remus, M. Schmitt, C. Kolopp, M-A. Westwood, N. Desjonquères, E. Brabet, S. Hell, K. LePoupon, A. Vermeulen, R. Jaisson, V. Rithié, G. Upert, A. Lederer, P. Zbinden, A. Wach, K. Moehle, K. Zerbe, H. H. Locher, F. Bernardini, G. E. Dale, L. Eberl, B. Wollscheid, S. Hiller, J. A. Robinson, D. Obrecht, Nature 2019, 576, 452, https://doi.org/10.1038/s41586-019-1665-6.

[14] D. Tomasek, S. Rawson, J. Lee, J. S. Wzorek, S. C. Harrison, Z. Li, D. Kahne, Nature 2020, 583, 473, https://doi.org/10.1038/s41586-020-2370-1.

[15] P. Fehlbaum, P. Bulet, S. Chernysh, J-P. Briand, J-P. Roussel, L. Letellier, C. Hetru, J. A. Hoffmann, Proc. Natl. Acad. Sci. USA 1996, 93, 1221, https://doi.org/10.1073/pnas.93.3.1221.

[16] a) S. U. Vetterli, K. Zerbe, M. Müller, M. Urfer, M. Mondal, S-Y. Wang, K. Moehle, O. Zerbe, A. Vitale, G. Pessi, L. Eberl, B. Wollscheid, J. A. Robinson, Sci. Adv. 2018, 4, eaau2634, https://doi.org/10.1126/sciadvaau2634; b) E. C. C. M. Moura, T. Baeta, A. Romanelli, C. Laguri, A. M. Martorana, E. Erba, J-P. Simorre, P. Sperandeo, A. Polissi, Front. Microbiol. 2020, 11, 909, htpps://doi.org/10.3389/fmicb.2020.00909.

[17] N. Mandard, P. Sodano, H. Labbe, J-M. Bonmatin, P. Bulet, C. Hetru, M. Ptak, F. Vovelle, Eur. J. Biochem. 1998, 256, 404, https://doi.org/10.1046/j.1432-1327.1998.2560404.x.

[18] a) U. M. Domanska, J. C. Boer, H. Timmer-Bosscha, M. A. T. M. van Vugt, H. D. Hoving, N. M. Kliphuis, S. Rosati, H. G. van der Poel, I. J. de Jong, E. G. E. de Vries, A. M. E. Walenkamp, Clin. Exp. Metastasis 2014, 31, 829, https://doi.org/10.1007/s10585-014-9673-2; b) D. M Ramsey, S. R. McAlpine, Bioorg. Med. Chem. Lett. 2013, 23, 20, https://dx.doi.org/10.1016/j.bmcl.2012.10.138.

[19] a) D. Peng, B. Cao, Y-J. Zhou, Y-Q. Long, Eur. J. Med. Chem. 2018, 149, 148, https://doi.org/10.1016/j.ejmech.2018.02.043; b) S. Oishi, N. Fujii, Org. Biomol. Chem. 2012, 10, 5720, https://doi.org/10.1039/C2OB25107H; c) M. J. Costa, J. Kudaravalli, W-H. Liu, J. Stock, S. Kong, S-H. Liu, PLoS ONE 2018, 13, e0194688, https://doi.org/10.1371/journal.pone.0194688; d) S. Jähnichen, C. Blanchetot, D. Maussang, M. Gonzalez-Pajuelo, K. Y. Chow, L. Bosch, S. De Vrieze, B. Serruys, H. Ulrichts, W. Vandevelde, M. Saunders, H. J. De Haard, D. Schols, R. Leurs, P. Vanlandschoot, T. Verrips, M. J. Smit, Proc. Natl. Acad. Sci. USA 2010, 107, 20565, https://doi.org/10.1073/pnas.1012865107.

[20] S. J. DeMarco, H. Henze, A. Lederer, K. Moehle, R. Mukherjee, B. Romagnoli, J. A. Robinson, F. Brianza, F. O. Gombert, S. Lociuro, Ch. Ludin, J. W. Vrijbloed, J. Zumbrunn, J-P. Obrecht, D. Obrecht, V. Brondani, F. Hamy, T. Klimkait, Bioorg. Med. Chem. 2006, 14, 8396, https://doi.org/10.1016/j.bmc.2006.09.003.

[21] H. Nakashima, M. Masuda, T. Murakami, Y. Koyanagi, A. Matsumoto, N. Fujii, N. Yamamoto, Antimicrob. Agents Chemother. 1992, 36, 1249, htpps://doi.org/10.1128/AAC.36.6.1249.

[22] H. Tamamura, M. Kuroda, M. Masuda, A. Otaka, S. Funakoshi, H. Nakashima, N. Yamamoto, M. Waki, A. Matsumoto, J. M. Lancelin, D. Kohda, S. Tate, F. Inagaki, N. Fujii, Biochim. Biophys. Acta (BBA) 1993 1163, 209, https://doi.org/10.1016/0167-4838(93)90183-R. 
[23] H. Tamamura, A. Omagari, S. Oishi, T. Kanamoto, N. Yamamoto, S. C. Peiper, H. Nakashima, A. Otaka, N. Fujii, Bioorg. Med. Chem. Lett. 2000, 10, 2633, https://doi.org/10.1016/S0960-894X(00)00535-7.

[24] B. Wu, E. Y. T. Chien, C. D. Mol, G. Fenalti, W. Liu, V. Katritch, R. Abagyan, A. Brooun, P. Wells, F. C. Bi, D. J. Hamel, P. Kuhn, T. M. Handel, V. Cherezov, R. C. Stevens, Science 2010, 330, 1066 htpps://doi.org/10.1126/science.1194396.

[25] a) G. D. Luker, J. Yang, A. Richmond, S. Scala, C. Festuccia, M. Schottelius, H-J. Wester, J. Zimmermann, J. Leukocyte Biol. 2020, 1-20, https://doi.org/10.1002/JLB.2BT1018-715RR; b) M. Martin, I. A. Mayer, A. M. E. Walenkamp, C. Lapa, M. Andreeff, A. Bobirca, J. Leukocyte Biol. 2020, 1-15, https://doi.org/10.1002/JLB.5BT1219-714R.

[26] E. A. R. Sison, D. Magoon, L. Li, C. E. Annesley, B. Romagnoli, G. J. Douglas, G. Tuffin, J. Zimmermann, P. Brown, Oncotarget 2015, 6, 30902, htpps://doi.org/10.18632/oncotarget.5094.

[27] a) D. Karpova, J. K. Ritchey, M. S. Holt, G. Abou-Ezzi, D. Monlish, L. Batoon, S. Millard, G. Spohn, E. Wiercinska, E. Chendamarai, W. Yang, S. Christ, L. Gehrs, L. G. Schuettpelz, K. Dembowsky, A. R. Pettit, M. P. Rettig, H. Bonig, J. F. DiPersio, Blood 2017, 129, 2939, https://doi.org/10.1182/blood-2016-10-746909; b) J. F. DiPersio, I. N. Micallef, P. J. Stiff, B. J. Bolwell, R. T. Maziarz, E. Jacobsen, A. Nademanee, J. McCarty, G. Bridger, G. Calandra, J. Clin. Oncol. 2009, 27, 4767, https://doi.org/10.1200/JCO.2008.20.7209.

[28] A. Müller, B. Homey, H. Soto, N. Ge, D. Catron, M. E. Buchanan, T. McClanahan, E. Murphy, W. Yuan, S. N. Wagner, J. L. Barrera, A. Mohar, E. Verástegui, A. Zlotnik, Nature 2001, 410, 50, https://doi.org/10.1038/35065016.

[29] Z. Zhang, C. Ni, W. Chen, P. Wu, Z. Wang, J. Yin, J. Huang, F. Qiu, BMC Cancer 2014, 14, 49, https://doi.org/10.1186/1471-2407-14-49.

[30] J. Xiang, M. A. Hurchla, F. Fontana, X. Su, S. R. Amend, A. K. Esser, G. J. Douglas, C. Mudalagiriyappa, K. E. Luker, T. Pluard, F. O. Ademuyiwa, B.
Romagnoli, G. Tuffin, E. Chevalier, G. D. Luker, M. Bauer, J. Zimmermann, R. L. Aft, K. Dembowsky, K. N. Weilbaecher Mol. Cancer Ther. 2015, 14, 2473, htpps://doi.org/10.1158/1535-7163.MCT-15-0252.

[31] S. Pernas, M. Martin, P. A. Kaufman, M. Gil-Martin, P. Gomez Pardo, S. Lopez-Tarruella, L. Manso, E. Ciruelos, J. A. Perez-Fidalgo, C. Hernando, F. O. Ademuyiwa, K. Weilbaecher, I. Mayer, T. J. Pluard, M. Martinez Garcia, L. Vahdat, J. Perez-Garcia, A. Wach, D. Barker, S. Fung, B. Romagnoli, J. Cortes, Lancet Oncol. 2018, 19, 812, https://doi.org/10.1016/S1470-2045(18)30147-5.

[32] D. Obrecht, J. Zimmermann. AACR Annual Conference 2021 Poster 3965, Permanent Abstract Number 414, Session 'Clinical Endocrinology'.

[33] J. Cortes, J. O’Shaughnessy, D. Loesch, J. L. Blum, L. T. Vahdat, K. Petrakova, P. Chollet, A. Manikas, V. Diéras, T. Delozier, V. Vladimirov, F. Cardoso, H. Koh, P. Bougnoux, C. E. Dutcus, S. Seegobin, D Mir, N. Meneses, J. Wanders, C. Twelves, Lancet 2011, 377, 914 https://doi.org/10.1016/S0140-6736(11)60070-6.

\section{License and Terms}

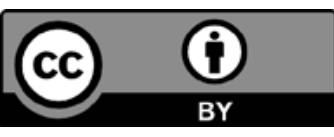

This is an Open Access article under the terms of the Creative Commons Attribution License CC BY 4.0. The material may not be used for commercial purposes.

The license is subject to the CHIMIA terms and conditions: (http:// chimia.ch/component/sppagebuilder/?view=page \&id=12).

The definitive version of this article is the electronic one that can be found at https://doi.org/10.2533/chimia.2021.508 